\title{
DOES HEURISTIC BEHAVIOR LEAVE ANOMALIES IN THE CAPITAL MARKET?
}

\author{
Shafiera Lazuarni ${ }^{1,}$ Marwan Asri ${ }^{2}$ \\ ${ }^{1}$ Management Study, Faculty of Economics, Indo Global Mandiri University, Palembang, 40262, \\ Indonesia \\ ${ }^{2}$ Department of Management, Faculty of Economics and Business, Universitas Gadjah Mada, \\ Yogyakarta, 55281, Indonesia
}

\begin{abstract}
Introduction/Main Objectives: This study aims to examine the role of heuristic behavior toward the formation of fundamental and technical anomalies in the capital market. This study also aims to examine the role of fundamental and technical anomalies on investment performance. Background Problems: Efficient Market Hypothesis (EMH) is not always able to explain all of the events or phenomena so that it still raises questions and produces research results that do not meet expectations, so in the end these phenomena are categorized as market anomalies. This study investigates whether heuristics have an effect on fundamental and technical anomalies and whether the anomalies have an effect on investment performance. Novelty: There is no research that uses hindsight variables incorporated into heuristics; therefore, this study confirms that the indicators used for hindsight measurements are appropriate for measuring what will be measured. Previous research did not involve hindsight in the heuristic category. Research Methods: Data management are done by using Structural Equation Modelling (SEM) with the help of the WarpPLS analysis tool. Mediation exploration testing was accomplished with variance accounted for (VAF). Findings/Results: The results of the study show that heuristics (availability, representativeness, and hindsight) are proven to be one of the factors that cause fundamental and technical anomalies in the capital market, except for availability heuristics. Conclusion: A large number of anomalies in the capital market do not stop investors from continuing to invest, so that at a certain level, investors are satisfied with their investments' performance because they use heuristics in an efficient way.
\end{abstract}

ARTICLE INFO

\footnotetext{
* Corresponding Author at Department of Management, Faculty of Economics and Business, Universitas Gadjah Mada, Jalan Socio Humaniora No. 1, Yogyakarta 55182, Indonesia.

E-mail address: shafieralazuarni@uigm.ac.id, marwan.asri@ugm.ac.id 


\section{INTRODUCTION}

Investors' interests in investing funds in the capital market show an increase. According to OJK (2018), the volume of shares traded from 2015 to 2017 continued to enlarge from (in millions) $1,459,101.78$ sheets to $1,946,284.30$ sheets in 2016 and 2,913,246.48 sheets in 2017; these will enhance people's interest in investing in the Indonesian capital market.

The theory relating to the information in the capital market is the efficient market hypothesis (EMH). In reality, the EMH is not always able to explain all of the events or phenomena. This is categorized as a market anomaly. Pompian \& Wood (2006) classified anomalies into fundamental, technical and calendar anomalies. Pompian \& Wood (2006) defined fundamental anomalies as a form of unfamiliarity that arises when the valuation of a stock's performance uses only a small proportion of the fundamental assessment, whereas technical anomalies refer to anomalies in financial trading instruments caused by technical analysis elements.

Researchers have proposed several behavioral theories to complement the existing financial models. Shefrin (2007) wrote that behavioral finance is the study of how this psychology can impact a person's financial behavior. Tversky \& Kahneman (1974) defined heuristics as a rule of thumb, which individuals use in situations of uncertainty to make simple and efficient decisions. Asri (2015) divided heuristics in three: the tendency to use available information (availability), simplification of the decision-making processes related to experience (hindsight), and behavior that assesses something like a reflection of the group that is represented (representativeness).

After observing the behavior of investors in Indonesia on several telegram groups, researchers found that the majority of investors abide by the technical analysis. Further, they ignore the fundamental analysis that underlies the stock. Besides, they are too quick when making decisions to sell or buy shares based on someone's advice or news from the group. This indicates that most Indonesian investors simplify information and their behavior, which could lead to fundamental and technical anomalies in the capital market, but they are still happy with their portfolios. This is supported by the results of a survey that we conducted. We found 214 (58\%) of our respondents had less than one year's experience of investing. Therefore, it makes sense for them to immediately follow the guidance of others in the group, since their investment experience is still limited.

Previous research related to heuristics, such as the research conducted by Rasheed et al., (2018); Gigerenzer \& Gaissmaier, (2011); Kurz \& Gigerenzer (2007), focused on how heuristics (availability, representativeness, hindsight) influence investors' decision making, furthermore research using a mediating variable is still scarcely available. Only one study was conducted involving mediation variables; this study was conducted by Abdin et al., (2017). They conducted a test on how the influence of heuristics on investment decisions and investment performance was mediated by fundamental anomalies and technical anomalies.

The study by Abdin et al. (2017) was conducted by using overconfidence, representativeness, availability, and anchoring as its variables. According to the justification of the study conducted by Abdin et al., (2017), the overconfidence and anchoring variables are not properly used as proxies to measure heuristics (the behavior of simplifying the decision-making process). Overconfidence is one of the groups' biases in understanding information and adjustment, and then the anchoring variable is one of the biases found in the group's biased reaction to information (Asri, 2015). 
This study uses more appropriate variables, for instance, adding hindsight variables as independent variables. The first objective of this study is to examine the effect of availability, representativeness, and the hindsight heuristics of investors on the formation of fundamental anomalies and technical anomalies in the capital market, and secondly to examine the effect of fundamental anomalies and technical anomalies on investment performance. According to Abdin et al. (2017), the mediating role of fundamental anomalies is significant between heuristics and investment performance, but not for technical anomalies. The technical anomalies' findings oppose the behavioral finance theory, which says that an investor is satisfied with his/her investment's performance, even with the existence of anomalies (Ivković \& Weisbenner, 2005; Kaniel et al., 2012; Grinblatt et al., 2012). Therefore, this study will conduct the same test to make sure of the results using different variables.

Data management are done by using SEM with WarpPLS as an analysis tool. Mediation exploration testing is undertaken with the variance accounted for (VAF) method. The results of the study show that heuristics are proven to be one of the factors that cause fundamental and technical anomalies in the capital market, except for availability heuristics. The results of exploration mediation found that the fundamental anomalies partially mediated the relationship between the representativeness and hindsight variables on investment performance, but did not mediate the relationship between the availability of investment performance and representativeness variables on investment performance. Furthermore, technical anomalies cannot explain the relationship between the availability and representativeness variables on investment performance, but technical anomalies partially mediated the relationship between hindsight and investment performance.

This research is important because it can provide information to investors that a large number of anomalies in the capital market can also have a positive effect on their investments' performance if they use heuristics in an efficient way. In addition, this research is actually useful for investors in Indonesia to understand how to have better investment decision-making processes.

\section{LITERATURE REVIEW}

\section{Heuristics}

Tversky \& Kahneman (1974) state that heuristics can help in many situations, but also lead to biased decisions, such as selling shares that are increasing in value too quickly and holding losing shares for too long (Odean, 1998), trading excessively and under-diversifying a portfolio (Goetzmann \& Kumar, 2008). Asri (2015) divides heuristics into three types called availability, hindsight, and representativeness. Availability is a cognitive heuristic that refers to a person's tendency to rely on information that is already available. Waweru et al., (2008) stated that availability is one of the forms in the heuristics group when viewed from the stock trading area.

Representativeness behavior is defined by Tversky \& Kahneman (1974) as a tendency to simplify the way to draw conclusions, namely by assuming that something that is faced is representative of a certain group even though the group is not necessarily represented. DeBondt \& Thaler (1995) state that the representativeness of heuristics makes investors optimistic about the future if they have made profits in the past, and will be pessimistic about the future if they suffered losses in the past and, as a result, they 
are satisfied with their investment decisions and performance.

Hindsight refers to a person's tendency to believe that he/she can predict the future, or an event in the future, based on the last event he/she experienced. Asri (2015) mentions the impact caused by hindsight; first, people become overly confident in their ability to predict events. Secondly, people will take too many risks. Thirdly, people will delay the sale of poorly performing shares because they feel the price should not be that bad, and finally, a manager delays a planned acquisition because he/she is afraid he/she will regret the decision, even though "I knew-it-all-along."

\section{Fundamental Anomalies and Technical Anomalies}

The most popular method used to calculate the value of an investment in stocks is fundamental analysis. It is also often ignored by investors (De Souza et al., 2018; Richards \& Willow, 2018; Khan et al., 2017; Barber \& Odean, 2008). Decision making that depends on heuristics can cause anomalies in the stock market.

Pompian \& Wood (2006) defined fundamental anomalies as a form of unfamiliarity that arises when the valuation of a stock's performance uses only a small proportion of the assessment fundamentals. Fundamental anomalies, if associated with behavior, will occur when investors focus on popular stocks and ignore the fundamentals of the stock; these fundamental anomalies can also occur when investors overreact to price changes (Abdin et al., 2017).

The EMH shows that stock prices in the capital market reflect all the relevant information. The basic concept behind the formation of technical analysis is contrary to EMH. Pompian \& Wood (2006) stated that this inconsistency between technical analysis and the efficient market hypothesis would ultimately form technical anomalies in the capital market, in other words, technical anomalies refer to anomalies in financial trading instruments caused by technical analysis elements.

\section{Investment Performance}

Investment performance can be defined as the rate of return on the investment portfolio owned by investors (Feibel \& Bruce, 2013). In this study, investment performance will be measured by investors' perceptions of the return they receive and the level of satisfaction with the investors' investments. Self-perception is illustrated as emotions arising from the experience of certain events, or their relationships to something (Bem, 1972).

Bem (1972), in his psychological research, stated that the result of perception is attitude. It represents whether someone likes or dislikes a person, place, thing, or event. As we expect, all investors like profits, and do not like losses; therefore, investors' perceptions about their investments can be indicated by them earning the return they expected or not.

\section{Development of Hypotheses}

\subsection{Availability, Fundamental Anomalies, and Technical Anomalies}

One of the complexities faced by investors when making decisions about the capital market is to determine which stocks to buy. Odean (1999) suggests that investors can limit their search to stocks that have recently caught their attention. This finding is also supported by the research of De Souza et al., (2018); and Yuan (2015) who found that investor attention is positively related to the trading volume. This phenomenon forces investors to look for stocks that are popular, rather than them looking for value in the shares.

The decision-making process that is often done will usually go through availability heuristics because this experience is inherent in the 
memory of the decision-maker and data, information along with all the things also needed as if enough memory is available so that no additional information is required (Asri, 2017). Abdin et al., (2017) stated that besides choosing popular stocks, investors would also buy local shares rather than foreign stocks. Cognitive limitations in processing all the available information will make it difficult for investors to find out the fundamental values underlying each stock; this will also push investors to pay more attention to popular stocks that are being discussed or that attract their attention, and even make them pay more attention to stock price movements. Ultimately this action will form the fundamental anomalies in the capital market. Abdin et al., (2017) proved the existence of a positive influence on the availability heuristic of fundamental anomalies.

H1a: The availability of heuristics owned by investors has a positive effect on the occurrence of fundamental anomalies in the capital market.

The majority of investors use past prices, trading volumes, and daily returns as indicators when choosing stocks (Kirkpatrick \& Dahlquist, 2010; Pompian \& Wood, 2006) and use technical analysis to predict stock prices in the future. By using technical analysis, investors use historical data and do not measure the intrinsic value of the shares, whereas technical analysis alone is not enough to conclude if the stock is good or not. Therefore, when investors use technical analysis to select stocks, these investors tend to ignore the assumptions of the efficient market hypothesis, and in the end, these activities produce technical anomalies in the stock market. Based on the research of Abdin et al, (2017), they found that the higher the level is of availability heuristics owned by investors, the greater the probability is of the occurrence of technical anomalies in the capital market.

H1b: The availability of heuristics owned by investors has a positive effect on the occurrence of technical anomalies in the capital market.

\subsection{Representativeness, Fundamental Anomalies, and Technical Anomalies}

Representativeness is associated with capital markets. Rasheed et al. (2018) stated that investors tend to use mental shortcuts and practical rules when making decisions to invest in companies, based only on their characteristics such as the type of management, past returns, or the popularity of the company.

Representativeness also leads investors to make irrational decisions by forcing them to overreact to "hot stocks" rather than underperforming stocks.. As a result, investors will focus on "hot stocks" and ignore the fundamental analysis of these stocks, which may lead the investors to the wrong conclusions. Abdin et al., (2017) added that investors often use the analysis of past trends from representative stocks to make investment decisions and will ultimately create fundamental anomalies in the capital market. Abdin et al., (2017) also proved that there is a positive influence from the representativeness heuristics that investors have on fundamental anomalies.

H2a: Representativeness heuristics owned by investors have a positive effect on the occurrence of fundamental anomalies in the capital market.

Representativeness makes investors mark whether the investment is good or bad. As a result, they buy shares when prices have risen and expect the increase to continue and ignore stocks when the price is below its intrinsic value. 
According to the theory of heuristics, investors use history to buy "hot stocks" and avoid bad stocks (Waweru et al., 2008). Representativeness also encourages investors to base their valuations on inadequate data samples when analyzing certain investments and by using technical analysis based on past representations to select stocks and ultimately create technical anomalies in the capital market. Abdin et al., (2017) proved that the higher the level of representativeness heuristics that investors have, the greater the probability of the occurrence of technical anomalies in the capital market.

H2b: Representativeness heuristics that investors possess have a positive effect on the occurrence of technical anomalies in the capital market.

\subsection{Hindsight, Fundamental Anomalies, and Technical Anomalies}

Barber \& Odean (2000) suggest that investors tend to be influenced by events in the stock market that attract their attention. Hindsight refers to a person's tendency to believe that he/she can predict the future or an event in the future, based on the last event he/she experienced. Asri (2015) stated that the impact caused by hindsight is excessive self-confidence and risk taking. As a result, they will trade excessively to obtain a high level of returns (Evans, 2006). When an investor trades, he/she will tend to make decisions based on his/her experience and the last event he/she experienced so that he/she ignores the fundamentals of the stock and will ultimately produce fundamental anomalies in the capital market.

H3a: Hindsight heuristics owned by investors have a positive influence on the occurrence of fundamental anomalies in the capital market.
According to the heuristic theory, investors use past prices and trends derived from their experience, cognitive abilities, and skills to predict future profits. One of the familiar tools used to assess stock prices is technical analysis. Technical analysis can also be interpreted as a technique for predicting the direction of stock price movements, based on historical data (Tandelilin, 2011).

Most non-experts believe that they can predict future trends based on past and current information. By using history and following previous trading experience based on technical analysis, investors assume that they can beat the market. Manic (2017) adds that most investors use technical analysis and assume that technical analysis benefits them in making investment decisions. Overall, the more someone uses the hindsight heuristic for making investment decisions, this means that the person will often trade on the stock market, so that person will also have more experience; then by using his/her trading experience based on the technical analysis, he/she will continuously do the same because they consider their intuition to be reliable and able to provide more benefits. This is what ultimately creates technical anomalies in the capital market.

H3b: Hindsight heuristics owned by investors have a positive effect on the occurrence of technical anomalies in the capital market.

\subsection{Fundamental Anomalies and Investment Performance}

Changes in stock prices influence investment behavior and investment performance (Waweru et al., 2008); changes in stock prices can also capture the attention of investors. Several studies, including those by Hillert \& Ungeheuer (2016); Hillert et al., (2014); De Souza et al., 
(2018); Yuan (2015); Fink \& Johann (2014); and Hu et al., (2013), have proven that the things that attract investors' attention can increase the number of trades carried out. Odean (1998) also argues that investors tend to choose stocks that attract their attention regardless of the fundamentals of the stocks, which can ultimately affect the performance of the investment.

Investors estimate future stock prices based on past prices, with the belief that financial data reflects all the information. Abdin et al., (2017) proved that a large number of anomalies in the capital market do not stop investors from continuing to invest, so that at a certain level investors feel satisfied with the performance of their investments.

H4: Fundamental anomalies have a positive effect on investment performance.

\subsection{Technical Anomalies and Investment Performance}

Individual investors often depend on decision making based on technical analysis to get abnormal returns from stock buying and selling transactions (Manic, 2017). Shleifer \& Summers (1990) state that trader noise is one illustration of investors who rely on technical analysis and are not dependent on information. Abdin et al., (2017) added that even if trader noise fails to obtain the desired return, they will remain satisfied with their performance. In conclusion, investors will use technical analysis to facilitate the information's interpretation and to predict future prices, make investment decisions and ultimately lead to technical anomalies in the capital market, which can also affect the performance of their investments. Manic (2017) proves that investors who use technical analysis in their investment valuations are satisfied with the returns they receive.
H5: Technical anomalies have a positive effect on investment performance.

\section{METHOD, DATA, AND ANALYSIS}

\section{Sample and Data}

This study used primary data. Individuals who are sampled must meet the following criteria: first, they must invest in financial instruments in the form of shares, and second have a securities account with a securities company in Indonesia. There were 375 investors participating as respondents. From those, six were deleted as they were outliers.

\section{Data Collection}

The survey method was used; data were collected by distributing questionnaires directly to the respondents, who filled them in and returned them. Indicators for the variables used in the study come from a previous study by Abdin et al., (2017) which supplied the indicators that measure availability, representativeness, fundamental anomalies, technical anomalies, and investment performance variables; the indicator for measuring the hindsight variable was provided by the study conducted by Sahi et al., (2013). A Likert scale from 1 to 5 was used.

\section{Measures}

Data management are done by using SEM with WarpPLS as an analysis tool. SEM-PLS analysis is grouped into two approaches. The first approach tested the measurement (to assess the quality and suitability of the model and the value of $\mathrm{p}$, and to test the construct's validity and reliability). The second approach tested the structural model (assessing the coefficients of determination, predictive relevance, the path coefficient, and p-value, the effect's size for each path, and the last test was with a control variable). 
The initial step that must be done before testing the value of VAF is by testing the role of mediation using the methods devised by Baron \& Kenny (1986). After obtaining the direct and indirect effects of mediation, testing using the VAF method can be done. The equation used in calculating the VAF method is

\section{VAF: Indirect Effect/Total Effect}

Conclusions of the mediation: If the value of VAF $>80 \%$, then the mediation is a full one. If the value of $\mathrm{VAF}>20 \%$ and $<80 \%$ then the mediation is a partial one. If the value of VAF $<$ $20 \%$, then there is no mediating effect.

\section{RESULT AND DISCUSSION}

\section{Respondent Background}

There were 369 investors who participated as the respondents, 317 were men $(85.9 \%)$, while the female respondents numbered only 52 (14.1\%).
One hundred and thirty-seven respondents were aged 20 years to less than 30 years old, and 229 $(62.1 \%)$ of the respondents were married. The majority of the respondents (226) had a bachelor's degree, while $214(58 \%)$ of the respondents had less than one year's investment experience, 213 respondents had a monthly income of more than Rp.5,000,000 and the majority of respondents (263) were employees. When viewed from the investors' group almost all the respondents were active investors, namely 364 out of the $369(98.6 \%)$.

\section{Hypotheses Testing}

Testing of the hypotheses begins by evaluating the quality and suitability of the model, and the value of $p$. The results already meet the criteria. Furthermore, the researchers conducted validity and reliability tests, the results can be seen in the following tables.

Table 1. Combined loading and cross-loading before deleting the indicators

\begin{tabular}{|c|c|c|c|c|c|c|c|}
\hline & AV & RP & HI & FA & TA & IP & $P$ Value \\
\hline AV1 & $(0.764)$ & & & & & & $<0.001$ \\
\hline AV2 & $(0.764)$ & & & & & & $<0.001$ \\
\hline RP1 & & $(0.804)$ & & & & & $<0.001$ \\
\hline RP2 & & $(0.804)$ & & & & & $<0.001$ \\
\hline HI1 & & & $(0.626)^{b}$ & & & & $<0.001$ \\
\hline HI2 & & & $(0.667)^{b}$ & & & & $<0.001$ \\
\hline HI3 & & & $(0.742)$ & & & & $<0.001$ \\
\hline HI4 & & & $(0.650)^{b}$ & & & & $<0.001$ \\
\hline HI5 & & & $(0.099)^{\mathrm{a}}$ & & & & $<0.001$ \\
\hline FA1 & & & & $(0.790)$ & & & 0.027 \\
\hline FA2 & & & & $(0.743)$ & & & $<0.001$ \\
\hline FA3 & & & & $(0.711)$ & & & $<0.001$ \\
\hline FA4 & & & & $(0.416)^{\mathrm{b}}$ & & & $<0.001$ \\
\hline TA1 & & & & & $(0.830)$ & & $<0.001$ \\
\hline TA2 & & & & & $(0.830)$ & & $<0.001$ \\
\hline IP1 & & & & & & $(0.908)$ & $<0.001$ \\
\hline IP2 & & & & & & $(0.890)$ & $<0.001$ \\
\hline IP3 & & & & & & $(0.785)$ & $<0.001$ \\
\hline
\end{tabular}

Note: ${ }^{\mathrm{a}}$ Loading $<0.4,{ }^{\mathrm{b}}$ Loading $0.4<\mathrm{x}<0.7$

Source: Data processed 
Table 2. Value of reliability parameters before and after deleting indicators

\begin{tabular}{ccc}
\hline $\begin{array}{c}\text { Thdi- } \\
\text { cators }\end{array}$ & $\begin{array}{c}\text { The average } \\
\text { variance extracted } \\
\text { (AVE) before } \\
\text { deleting the } \\
\text { indicator }\end{array}$ & $\begin{array}{c}\text { The average } \\
\text { variance extracted } \\
\text { (AVE) after } \\
\text { deleting the } \\
\text { indicator }\end{array}$ \\
\hline AV & 0.584 & 0.584 \\
RP & 0.646 & 0.646 \\
HI & $0.364^{\mathrm{a}}$ & 0.529 \\
FA & $0.464^{\mathrm{a}}$ & 0.590 \\
TA & 0.690 & 0.690 \\
IP & 0.744 & 0.744 \\
\hline Note ${ }^{\mathrm{a}} \mathrm{AVE}<0.5$ &
\end{tabular}

Source: Data processed

Table 3. Square roots AVE

\begin{tabular}{|c|c|c|c|c|c|c|}
\hline & AV & $\mathbf{R P}$ & HI & FA & TA & IP \\
\hline$\overline{A V}$ & $(0.764)$ & & & & & \\
\hline RP & & $(0.804)$ & & & & \\
\hline HI & & & $(0.727)$ & & & \\
\hline FA & & & & $(0.768)$ & & \\
\hline TA & & & & & $(0.830)$ & \\
\hline IP & & & & & & (0.863) \\
\hline
\end{tabular}

Table 4. Value of reliability after deleting the indicators

\begin{tabular}{ccc}
\hline Indicators & $\begin{array}{c}\text { Cronbach's } \\
\text { Alpha }\end{array}$ & $\begin{array}{c}\text { Composite } \\
\text { Reliability }\end{array}$ \\
\hline AV & $0.287^{\mathrm{a}}$ & 0.737 \\
RP & $0.452^{\mathrm{a}}$ & 0.785 \\
HI & $0.549^{\mathrm{a}}$ & 0.769 \\
FA & $0.649^{\mathrm{a}}$ & 0.811 \\
TA & $0.550^{\mathrm{a}}$ & 0.816 \\
IP & 0.826 & 0.897 \\
\hline Cronbach's alpha $<0.7$ & \\
Source: Data processed &
\end{tabular}

Table 5. Coefficient value path and p-value

\begin{tabular}{lll}
\hline \multicolumn{1}{c}{ Hypothesis } & \multicolumn{1}{c}{ Path } & \multicolumn{1}{c}{$\boldsymbol{\beta}$} \\
\hline Hypothesis 1a & AV $\rightarrow$ FA & $0.106^{*}$ \\
Hypothesis 1b & AV $\rightarrow$ TA & 0.063 \\
Hypothesis 2a & RP $\rightarrow$ FA & $0.259^{* * *}$ \\
Hypothesis 2b & RP $\rightarrow$ TA & $0.200^{* * *}$ \\
Hypothesis 3a & HI $\rightarrow$ FA & $0.299^{* * *}$ \\
Hypothesis 3b & HI $\rightarrow$ TA & $0.422^{* * *}$ \\
Hypothesis 4 & FA $\rightarrow$ IP & $0.316^{* * *}$ \\
Hypothesis 5 & TA $\rightarrow$ IP & $0.072+$ \\
\hline
\end{tabular}

Note: $\quad(*$ significance 0.05$)(* *$ significance 0.01$)(* * *$ significance 0.001$)(+$ significance 0.10$)$

Source: Data processed

Table 6. The effect size for path coefficients

\begin{tabular}{lccl}
\hline \multicolumn{1}{c}{ Hypothesis } & Path & $\begin{array}{c}\text { Effect } \\
\text { Size }\end{array}$ & \multicolumn{1}{c}{ Note } \\
\hline Hypothesis 1a & AV $\rightarrow$ FA & 0.019 & Very weak \\
Hypothesis 1b & AV $\rightarrow$ TA & 0.009 & Very weak \\
Hypothesis 2b & RP $\rightarrow$ TA & 0.061 & Weak \\
Hypothesis 3a & HI $\rightarrow$ FA & 0.111 & Weak \\
Hypothesis 3b & HI $\rightarrow$ TA & 0.200 & Medium \\
Hypothesis 4 & FA $\rightarrow$ IP & 0.111 & Weak \\
Hypothesis 5 & TA $\rightarrow$ IP & 0.017 & Very weak \\
\hline Source: Data processed & &
\end{tabular}

The support for Hypothesis 1a proves that, to reduce the level of complexity which exists in the capital market, investors tend to rely on information that is already available. The support for this hypothesis also supports the findings of Odean (1999), suggesting that investors regulate the problem of choosing the number of shares that might be purchased by limiting their search to stocks that recently caught their attention. In the end, these phenomena force investors to look for stocks that are popular, rather than them looking for the underlying value in these shares.

Hypothesis $1 \mathrm{~b}$ is not supported. The researchers' main guess about why this hypothesis is not supported is because when investors acquire some information about stocks, they want to maximize their profits by being reactive and predictive of the information by using technical analysis (Kirkpatrick \& Dahlquist, 2010). Unfortunately, not all the information that investors obtain can be used for decision making, as expressed by Kirkpatrick \& Dahlquist (2010), investors who use technical analysis will react to certain market conditions to make their decisions.

Hypothesis 2a is supported; this supports the findings of Abdin et al. (2017), which states that investors often use the analysis of past trends 
from representative stocks to make investment decisions and will ultimately make fundamental anomalies in the capital market. This also proves that investors choose stocks that will represent the quality of the shares (Shefrin, 2007) and this irrational behavior can ultimately cause prices to stay away from their intrinsic values.

The support for Hypothesis $2 \mathrm{~b}$ confirms the findings of Abdin et al. (2017), who found a positive influence of representativeness on the occurrence of technical anomalies in the capital market. The support for this hypothesis also provides support for the theory of heuristics which states that investors use history to buy "hot stocks" and avoid bad stocks in their decision making (Waweru et al., 2008).

The support for Hypothesis 3a proves that when an investor has previously traded, he/she will tend to make decisions based on his/her experience so that the fundamentals of the stock are ignored. This finding proves that hindsight is also one of the factors that can lead to technical anomalies in the capital market. Someone who often trades in the stock market supports the statement of Manic (2017) which states that most investors use technical analysis in their investment decisions.

The support for Hypothesis 4 confirms the findings of Abdin et al., (2017) which prove that having a large number of anomalies in the capital market does not stop investors from continuing to invest. At a certain level investors feel satisfied with the performance of their investments. This also concludes that although investors only focus on popular stocks and ignore the fundamentals of the stocks, they will still be satisfied with the returns obtained, which reflect the performance of their investments. This finding also confirms the previous research of Grinblatt et al., (2012) who found that individual investors earn abnormal returns from the presence of anomalies in the capital market.
The support for Hypothesis 5 confirms the findings of Manic (2017) which prove that investors who use technical analysis in their investment valuations are also satisfied with the returns they earn, and also supports the findings of Kaniel et al., (2012) who found that individual investors gain abnormal returns from the presence of anomalies in the capital market. The results of the mediation exploration test can be seen in Table 7 below:

Table 7. Summary of mediation exploration tests using the VAF method

\begin{tabular}{ccl}
\hline \multicolumn{1}{c}{ Path } & VAF Value & \multicolumn{1}{c}{ Type of mediation } \\
\hline AV-FA-IP & $\mathbf{- 0 . 4 4 7}$ & No Mediating Effect \\
AV-TA-IP & $\mathbf{- 0 . 1}$ & No Mediating Effect \\
RP-FA-IP & $\mathbf{0 . 3 5 1}$ & Partial Mediation \\
RP-TA-IP & $\mathbf{0 . 1 8 5}$ & No Mediating Effect \\
HI-FA-IP & $\mathbf{0 . 4 1 7}$ & Partial Mediation \\
HI-TA-IP & $\mathbf{0 . 3 5 3}$ & Partial Mediation \\
\hline
\end{tabular}

Source: Data processed

Based on Table 7 above, it can be concluded that the FA variable does not mediate or does not explain the AV relationship with IP, the relationship is only limited to the path relationship. Table 7 explains that the FA partially mediates the relationship between the RP and HI variables toward IP because the VAF values possessed by the two variables are 0.351 (35.1\%) and 0.417 (41.7\%), respectively.

The TA variable is also not able to explain the relationship between AV and IP. TA also does not mediate the relationship between RP and IP because the VAF value is only 0.185 $(18.5 \%)$, or less than $20 \%$, while TA partially mediates the relationship between the HI variables and IP with a VAF value of 0.353 (35.3\%). The researchers' main guess about why fundamental and technical anomalies cannot explain the relationship between the availability of information and investment performance is because when investors gain some information about stocks; at that time they want to maximize 
their profits by being reactive and predictive of the information (Kirkpatrick \& Dahlquist, 2010). Unfortunately, not all the information that investors obtain is useful for decision making. Investors who both use and ignore technical analysis will react to certain market conditions when making decisions. When capital markets are deteriorating, most investors are unlikely to trade.

\section{CONCLUSION AND SUGGESTION}

Studies discussing heuristics, technical, and fundamental anomalies are scarce. Previous research into investors' behavior focused on how certain characteristics, personality types or events can influence an investor to make a decision. Previous research has also only focused on developed countries.

The results of this study evidenced that the simplifying behavior of information can influence the occurrence of anomalies in the capital market, and existing anomalies do not always harm investment performance. Therefore, this study can help investors to understand their behavior when choosing their shares and how they can have a better investment decisionmaking process. Securities companies can use the results of this study as an indicator to understand how real investors behave, analyze future market trends, and can provide advice that is more suitable to their investors, by relating it to activities in the capital market.

It should be emphasized that this study aims to determine the effect of heuristics on fundamental and technical anomalies, and their effect on investment performance. The mediating exploration mechanism is only an additional test, not the main focus of the research. Therefore, future research can explore the mediation relationship. Moreover, future research can identify how heuristics affect women and men, different types of work, investment experiences and capture in detail how investors behave when selling or buying shares.

\section{REFERENCE}

Abdin, S. Z., Farooq, O., Sultana, N., \& Farooq, M. (2017). The impact of heuristics on investment decision and performance: Exploring multiple mediation mechanisms. Research in International Business and Finance, 42, 674-688.

Asri, Marwan. (2015). Keuangan Keperilakuan. Yogyakarta: BPFE.

Barber, B. M., \& Odean, T. (2000). Trading is hazardous to your wealth: The common stock investment performance of individual investors. Journal of Finance, 55 (2), 773806.

Barber, B. M., \& Odean, T., (2008). All that glitters: The effect of attention and news on the buying behavior of individual and institutional investors. Review of Financial Studies, 21 (2), 785-818.

Baron, R. M., \& Kenny, D. A. (1986). The moderator-mediator variable distinction in social psychological research: Conceptual, strategic, and statistical considerations. Journal of Personality and Social Psychology, 51 (6), 1173-1182.

Bem, D. J. (1972). Self-perception theory (Reprinted from advances in experimental social psychology. Vol 6). Academic Press, Inc. New York and London.

De Souza, H. E., Barbedo, C. H. D. S., \& Araujo, G. S. (2018). Does investor attention affect trading volume in the Brazilian stock market? Research in International Business and Finance, 44, 480487.

Evans, D. A. (2006). Subject perceptions of confidence and predictive validity in financial information. Journal Behavioral Finance, 7 (1), 12-28.

Fink, C., \& Johann, T. (2014). May I have your attention, please: The market microstructure for investor attention. Please: The Market Microstructure of Investor Attention (September 17, 2014). 
Gigerenzer. G., \& Gaissmaier. W. (2011). Heuristic decision making. Annual Review of Psychology, 62, 451-482.

Goetzmann, W. N., \& Kumar, A. (2008). Equity portfolio diversification. Review of Finance, 12 (3), 433-463.

Grinblatt, M., Keloharju, M., \& Linnainmaa, J.T. (2012). IQ, trading behavior, and performance. Journal Finance Economic, 104 (2), 339-362.

Hillert, A., \& Ungeheuer, M. (2016). Ninety years of media coverage and the crosssection of stock returns. University of Mannheim, working paper.

Hillert, A., Jacobs, H., \& Müller, S. (2014). Media makes momentum. The Review of Financial Studies, 27 (12), 3467-3501.

Hu, N., Dong, Y., Liu, L., \& Yao, L. J. (2013). Not all that glitters is gold: The effect of attention and blogs on investors' investing behaviors. Journal of Accounting, Auditing \& Finance, 28 (1), 4-19.

Ivković, Z., \& Weisbenner, S. (2005). Local does as local is: Information content of the geography of individual investors' common stock investments. The Journal of Finance, 60 (1), 267-306.

Kaniel, R., Liu, S., Saar, G., \& Titman, S. (2012). Individual investor trading and return patterns around earnings announcements. The Journal of Finance, 67 (2), 639-680.

Khan, H. H., Naz, I., Qureshi, F., \& Ghafoor, A. (2017). Heuristics and stock buying decision: Evidence from Malaysian and Pakistani stock markets. Borsa Istanbul Review, 17 (2), 97-110.

Kirkpatrick II, C. D., \& Dahlquist, J. A. (2010). Technical analysis: The complete resource for financial market technicians. FT press.

Kurz. M. E., \& Gigerenzer, G. (2007). Heuristic decision making. Journal of Research and Management, 3 (1), 48-56.

Manic, Vukman. (2017). Investments based on technical analysis. (Master Thesis. Faculty of Economics and Administration. Masaryk: University Brno).
Odean, T. (1998). Volume, volatility, price, and profit when all traders are above average. The Journal of Finance, 53 (6), 1887-1934.

Odean, T. (1999). Do investors trade too much? American Economic Review, 89 (5), 1279 1298.

Pompian, M. M., \& Wood, A. S. (2006). Behavioral finance and wealth management: How to build optimal portfolios for private clients. New York, John Wiley \& Sons Inc.

Rasheed, M. H., Rafique, A., Zahid, T., \& Akhtar, M. W. (2018). Factors influencing investor's decision making in Pakistan: Moderating the role of locus of control. Review of Behavioral Finance, 10(1), 70-87.

Richards, D. W., \& Willows, G. D. (2018). Who trades profusely? The characteristics of individual investors who trade frequently. Global Finance Journal, Doi: 10.1016/ j.gfj.2017.03.006.

Sahi, S. K., Arora, A. P., \& Dhameja, N. (2013). An exploratory inquiry into the psychological biases in financial investment behavior. Journal of Behavioral Finance, 14 (2), 94-103.

Shefrin, H. (2007). Behavioral corporate finance: Decisions that create value. New York: Mc Grwall Hill/Irwin.

Shleifer, A., \& Summers, L. H. (1990). The noise trader approach to finance. Journal of Economic Perspectives, 4 (2), 19-33.

Tandelilin, Eduardus. (2011). Portofolio and investasi. Yogyakarta: Konisius.

Tversky, A., \& Kahneman, D. (1974). Judgment under uncertainty: Heuristics and biases. Science, 185 (415) 1124-1131.

Waweru, N. M., Munyoki, E., \& Uliana, E. (2008). The effects of behavioral factors in investment decision-making: A survey of institutional investors operating at the Nairobi Stock Exchange. International Journal of Business and Emerging Markets, 1 (1), 24-41.

Yuan Y. (2015). Market-wide attention, trading, and stock returns. Journal of Financial Economics, 116 (3), 548-564. 